\title{
Diet-related greenhouse gas emissions assessed by a food frequency questionnaire and validated using 7-day weighed food records
}

Camilla Sjörs $^{1 *}$, Sara E Raposo ${ }^{1,2}$, Arvid Sjölander ${ }^{1}$, Olle Bälter ${ }^{3,4}$, Fredrik Hedenus ${ }^{5}$ and Katarina Bälter ${ }^{1,6}$

\begin{abstract}
Background: The current food system generates about $25 \%$ of total greenhouse gas emissions (GHGE), including deforestation, and thereby substantially contributes to the warming of the earth's surface. To understand the association between food and nutrient intake and GHGE, we therefore need valid methods to assess diet-related GHGE in observational studies.

Methods: Life cycle assessment (LCA) studies assess the environmental impact of different food items. We linked LCA data expressed as $\mathrm{kg}$ carbon dioxide equivalents $\left(\mathrm{CO}_{2} \mathrm{e}\right)$ per $\mathrm{kg}$ food product to data on food intake assessed by the food frequency questionnaire (FFQ) Meal-Q and validated it against a 7-day weighed food record (WFR). 166 male and female volunteers aged 20-63 years completed Meal-Q and the WFR, and their food intake was linked to LCA data.

Results: The mean GHGE assessed with Meal-Q was $3.76 \mathrm{~kg} \mathrm{CO} \mathrm{CO}_{2} \mathrm{e}$ per day and person, whereas it was $5.04 \mathrm{~kg}$ $\mathrm{CO}_{2} \mathrm{e}$ using the WFR. The energy-adjusted and deattenuated Pearson and Spearman correlation coefficients were 0.68 and 0.70 , respectively. Moreover, compared to the WFR, Meal-Q provided a good ranking ability, with $90 \%$ of the participants classified into the same or adjacent quartile according to their daily average $\mathrm{CO}_{2} \mathrm{e}$. The BlandAltman plot showed an acceptable level of agreement between the two methods and the reproducibility of Meal-Q was high.

Conclusions: This is the first study validating the assessment of diet-related GHGE by a questionnaire. The results suggest that Meal-Q is a useful tool for studying the link between food habits and $\mathrm{CO}_{2} \mathrm{e}$ in future epidemiological studies.
\end{abstract}

Keywords: Validation studies, Reproducibility of results, Food frequency questionnaire, Weighed food record, Epidemiology, Greenhouse gas emission, Climate change, Life cycle assessment, Carbon dioxide equivalents, Sustainable diets

\footnotetext{
* Correspondence: Camilla.Sjors@ki.se

${ }^{1}$ Department of Medical Epidemiology and Biostatistics, Karolinska Institutet,

SE-171 77 Stockholm, Sweden

Full list of author information is available at the end of the article
} 


\section{Background}

The current production and distribution of food generates about $25 \%$ of total greenhouse gas emissions (GHGE), including deforestation, and thereby contributes to the warming of the earth's surface [1]. There are technical mitigation options to reduce GHGE, but dietary shifts will be necessary if the climate target of a maximum $2^{\circ}$ temperature increase is to be met with high certainty [2].

Although a healthy diet associated with low GHGE can meet nutritional requirements and may even bring health benefits compared to food habits with higher GHGE [3-7], not all low carbon diets are necessarily nutritious or leads to better health than a high carbon diet $[8,9]$. Models of health impacts from various dietary scenarios, e.g. cardiovascular disease, cancer and overall mortality, suggest that healthy diets with lower GHGE are in line with general public health goals [10-12]. However, until now, most studies on diet, GHGE and health outcomes are based on theoretical models, and need to be confirmed in observational studies based on habitual food consumption.

In order to study climate-friendly diets, data on dietary intake need to be linked to data on GHGE from life cycle assessment (LCA) studies [13]. This raises the issue of valid dietary assessment methods for studying dietrelated GHGE and health outcomes in large epidemiological studies. Lately, food frequency questionnaires (FFQs) have been used more frequently to estimate dietary GHGE. However, to our knowledge, this is the first study to specifically validate a FFQ's ability to estimate dietary GHGE.

The aim of this study is to validate the assessment of GHGE from diet using a FFQ called Meal-Q compared to a 7-day weighed food record (WFR), as well as to evaluate the reproducibility of Meal-Q.

\section{Methods}

The validation study VALMA (Validation of Methods Assessing diet and physical activity) has been described in detail elsewhere [14]. In brief, recruitment to the VALMA study took place in April 2009 in Stockholm County, Sweden, through public advertisements to the general population and students at universities. To be included, participants needed to have access to the Internet and an email address, not be trying to lose weight, not be pregnant and not have given birth within the past ten months. In total, 180 healthy male and female volunteers aged 20-63 years were enrolled. All participants provided informed consent. The questionnaires were sent out via e-mail and individual user names and passwords served as identifiers.

During the study, all participants responded to Meal$\mathrm{Q}$ once and completed a 7-day WFR. About half of the participants were asked to fill out Meal-Q a second time, three weeks after the first, to enable evaluation of reproducibility.

Exclusions were made due to dropout $(n=1)$, illness $(n=2)$ and energy underreporting $(n=11)$, leaving 166 participants for validation analyses, and 87 participants for analyses of reproducibility. There were no statistically significant differences in age, body mass index (BMI, $\mathrm{kg} / \mathrm{m}^{2}$ ), education level, fulltime workers, students, nutrition background, smokers and Swedish snuff users between included and excluded participants (data not shown).

The study was approved by the Research Ethics Committee at Karolinska Institutet.

Previous validation studies based on Meal-Q show that the questionnaire performs well regarding energy, macronutrients [14], fiber and micronutrients [15], although there were substantial variations for different nutrients. Crude daily intakes were overall higher in the 7-day WFR compared to Meal-Q. The energy-adjusted and deattenuated correlation coefficients ranged from 0.16 to 0.73, (e.g. 0.18 for energy and 0.33, 0.65 and 0.57 for protein, carbohydrates and total fat, respectively). The proportion of participants classified into the same or adjacent quartile ranged from 69 to $90 \%$, (e.g. $70 \%$ for energy and 76, 82 and 78\% for protein, carbohydrates and total fat, respectively).

\section{Food frequency questionnaire (FFQ)}

Meal-Q is a web-based FFQ assessing habitual dietary intake during the past few months, which includes predefined food items and intake frequencies. Respondents only fill in the food items that they eat at least once a month. The interactive format includes 102-174 food items, depending on the number of follow-up questions. To assess portion sizes of cooked dishes and vegetables the respondents choose between five photos with different amounts for each of the three following food groups: rice/potatoes/pasta, meat/chicken/fish/vegetarian substitutes, and raw/cooked vegetables. Standard portion sizes were used for all other food items.

\section{7-day weighed food records (WFR)}

At an introductory meeting, the participants received a household scale and oral and written instructions on how to record everything they ate and drank. During the WFR, participants reported their daily food intake through a web-based program covering more than 2000 food items. All WFRs were checked for completeness by the study personnel. Participants also recorded their physical activity by reporting the number of daily steps from a pedometer, as well as activities not captured by pedometers. This information was used to calculate each 
participant's physical activity level (PAL) to identify potential under-reporters of energy intake in the WFR.

\section{Diet-related GHGE}

We collected data from LCA studies for 65 food products or groups aiming at representing the average consumption pattern in Sweden (for LCA data see Additional file 1: Table S1).

The main diet-related greenhouse gases are methane, nitrous oxide and carbon dioxide. Methane is emitted from ruminants, rice cultivation and manure management, nitrous oxide from agriculture and manure management and carbon dioxide from transports and energy use during food production and processing.

All LCA studies included GHGE from agriculture and its inputs, and the majority also included emissions up to and including the retail phase. We adjusted all LCA data to include the same system boundaries, for example added standard emission factors from post-farm processes, including processing, packaging, distribution and retail [16]. Emissions after the retail phase (from transports, storing and cooking, as well as from waste management) were not included.

Carbon dioxide, methane and nitrous oxide have different global warming potential (GWP), and their combined effect is often presented as $\mathrm{kg}$ carbon dioxide equivalents $\left(\mathrm{CO}_{2} \mathrm{e}\right)$ per $\mathrm{kg}$ of food product [13]. The GWP used to calculate the $\mathrm{CO}_{2} \mathrm{e}$ was 1 for carbon dioxide, 34 for methane and 296 for nitrous oxide [17].

Portion sizes were reported in the form in which the products were consumed in both Meal-Q and WFR. We therefore recalculated LCA data for appropriate food items to the prepared form, considering both hydration, i.e. cooking of rice, and dehydration, i.e. cooking of meat [18].

We adjusted for unavoidable food losses (i.e. shell and bone) using data from the Swedish food composition database [18]. In addition we adjusted for avoidable food losses both before and after food preparation using data from the British Waste and Resources Action Programme [19] and a FAO report [20].

To calculate the $\mathrm{CO}_{2} \mathrm{e}$ for mixed dishes, up to three main food products or groups were weighted using standard recipes. Recipes from the Swedish food composition database were used when available [18]. Thereafter, LCA data on $\mathrm{CO}_{2} \mathrm{e}$ per $\mathrm{kg}$ food item were linked to all food items in Meal-Q and the WFR.

\section{Statistical analyses}

Descriptive results are presented as means and standard deviations (SD) or numbers of participants (n) and percentages (\%). The Wilcoxon-Mann-Whitney test was used to assess potential differences in age and BMI between included and excluded participants as well as between women and men. Further, Fisher's exact test was used to assess potential differences regarding education level, fulltime workers, students, nutrition background, smokers and Swedish snuff users.

The Goldberg cut-off method [21] was used to identify energy under-reporters. The cut-off value was calculated using the energy intake from the WFR together with the obtained PAL values from the physical activity record.

The residual method was used to adjust $\mathrm{CO}_{2} \mathrm{e}$ for total energy intake and a constant (the $\mathrm{CO}_{2} \mathrm{e}$ at the mean energy intake from Meal-Q) was added to the residuals [22]. Means, medians and interquartile ranges (IQRs) of crude and energy-adjusted $\mathrm{CO}_{2} \mathrm{e}$ were compared between Meal-Q and the WFR. To test the ranking agreement and magnitude of misclassification of Meal-Q compared to the WFR, quartile cross-classifications were used. Participants were divided into quartile categories of crude and energy-adjusted $\mathrm{CO}_{2} \mathrm{e}$ and the proportion of participants classified into the same, adjacent, and extreme quartiles were calculated. To evaluate absolute agreement and potential differences in bias within the $\mathrm{CO}_{2} \mathrm{e}$ range, the method of Bland and Altman was used, where the differences in $\mathrm{CO}_{2} \mathrm{e}$ between Meal-Q and WFR were plotted against the average of the two methods [23]. The plot provides a measure of variation represented by the limits of agreement, i.e., $\pm 2 \mathrm{SD}$ of the mean difference. Besides the Bland-Altman plot, a scatter plot was also used as graphical evaluation of the associations.

Spearman and Pearson correlation coefficients were used to measure the degree of association between Meal-Q and the WFR. For Pearson correlation coefficients the data were log transformed to improve the normality of the distribution. To remove effects of withinperson variation in the WFR, Pearson and Spearman correlation coefficients were deattenuated, using the formula of Beaton et al. [24] and Liu et al. [25]. The method of Willett and Rosner [26] was used to produce confidence intervals. The Wilcoxon signed rank test was used to test for differences between the methods.

Crude and energy-adjusted $\mathrm{CO}_{2} \mathrm{e}$ were compared between the first and second Meal-Q using the mean, median and IQRs. To evaluate the reproducibility, crude and energy-adjusted quartile cross-classifications of the first and second Meal-Q were made, as well as a scatter plot and a Bland-Altman plot. The Wilcoxon signed rank test was used to test for differences between the methods [23]. In addition, one-way ANOVA with random effects was used to compute intraclass correlation coefficients (ICCs) [27].

The significance level was set to $\alpha=.05$. All $p$-values were two-sided. Analyses were performed using STATA 13.1 (STATA Corporation, College Station, TX, USA). 


\section{Results}

The characteristics of the participants are shown in Table 1 . The mean age was 33 years, a majority of the participants had more than 12 years of education and almost $60 \%$ were students. Women had a lower BMI than men (22.9 vs 23.8) and more men than women used Swedish snuff. There were no statistically significant differences between gender with regards to age, education, working full time, students, nutrition background or smoking.

The GHGE assessed by the WFR was $5.04 \mathrm{~kg} \mathrm{CO}_{2} \mathrm{e}$ and statistically significantly higher than the $3.76 \mathrm{~kg}$ $\mathrm{CO}_{2} \mathrm{e}$ assessed by Meal-Q (Table 2). When participants were divided into quartiles according to their crude and energy-adjusted daily average $\mathrm{CO}_{2} \mathrm{e}, 42.8$ and $47.6 \%$ of the participants were classified into the same quartile. The proportions classified into the same or adjacent quartile were 81.3 and $90.4 \%$ respectively for crude and energy-adjusted daily average $\mathrm{CO}_{2} \mathrm{e}$, while 3.6 and $0.6 \%$ were classified into extreme quartiles.

A scatter and a Bland-Altman plot of energy-adjusted daily $\mathrm{CO}_{2} \mathrm{e}$ assessed with Meal-Q and WFR are displayed in Figs. 1 and 2, respectively. The plots visualize to what extent there are differences in assessment of $\mathrm{CO}_{2} \mathrm{e}$, comparing Meal-Q to the WFR. The scatter plot showed somewhat lower $\mathrm{CO}_{2}$ e by Meal-Q compared to the WFR. The Bland-Altman plot showed that Meal-Q had a daily mean underestimation of about $-1.28 \mathrm{~kg}$ $\mathrm{CO}_{2} \mathrm{e}$ and a trend of increasing underestimation with increasing $\mathrm{CO}_{2} \mathrm{e}$. The scatter and Bland-Altman plots for crude daily $\mathrm{CO}_{2} \mathrm{e}$ were similar (see Additional file 1: Fig. S1 and S2).

Table 3 shows Pearson and Spearman correlation coefficients. The crude, energy-adjusted, and deattenuated Pearson correlation coefficients were $0.56,0.67$ and 0.68 ,

Table 1 Characteristics of participants included in the validation analysis ( $n=166)$

\begin{tabular}{lllll}
\hline Characteristics & All & Women & Men & \\
& $(n=166)$ & $(n=132)$ & $(n=34)$ & \\
& Mean (SD) & Mean (SD) & Mean (SD) & $P$-value \\
\hline Age (years) & $32.9(11.6)$ & $32.9(11.9)$ & $32.6(10.3)$ & 0.9106 \\
BMl $\left(\mathrm{kg} / \mathrm{m}^{2}\right)$ & $23.1(3.6)$ & $22.9(3.8)$ & $23.8(2.2)$ & 0.0068 \\
& $\mathrm{n}(\%)$ & $\mathrm{n}(\%)$ & $\mathrm{n}(\%)$ & $P$-value \\
Education $>12$ years & $133(80)$ & $106(80)$ & $27(79)$ & 1.000 \\
Working full time & $55(33)$ & $43(33)$ & $12(35)$ & 0.839 \\
Student & $97(58)$ & $79(60)$ & $18(53)$ & 0.559 \\
Nutrition background $^{\mathrm{a}}$ & $49(30)$ & $43(33)$ & $6(18)$ & 0.097 \\
Smoking $^{\mathrm{b}}$ & $11(7)$ & $6(5)$ & $5(15)$ & 0.098 \\
Swedish snuff use $^{\mathrm{bc}}$ & $11(7)$ & $4(3)$ & $7(21)$ & 0.000 \\
\hline
\end{tabular}

BMI Body mass index

${ }^{a}$ Working or studying in the field of nutrition. ${ }^{b}$ Data missing for three women. ${ }^{\mathrm{c} S}$ wedish snuff (snus) is a moist powder tobacco product
Table $2 \mathrm{CO}_{2}$ e for participants included in the validation analysis

\begin{tabular}{llllllll}
\hline & \multicolumn{3}{c}{ Crude $\mathrm{kg} \mathrm{CO}_{2}$ e per day } & & \multicolumn{3}{c}{ Energy-adjusted $\mathrm{kg} \mathrm{CO}_{2} \mathrm{e}$ per day } \\
\cline { 2 - 3 } & Mean & Median & (IQR) & & Mean & Median & (IQR) \\
\hline WFR & 5.04 & 4.47 & $(2.67)$ & & 5.04 & 4.81 & $(2.36)$ \\
Meal-Q & 3.76 & 3.51 & $(1.83)$ & & 3.76 & 3.55 & $(1.69)$ \\
\% of WFR & 75 & 78 & & 75 & 74 & \\
\hline
\end{tabular}

Mean, median and IQR of daily $\mathrm{CO}_{2} \mathrm{e}$ for participants included in the validation analysis $(n=166)$

IQR Interquartile range, $\mathrm{CO}_{2} e$ Carbon dioxide equivalents, WFR Weighed food record. ${ }^{\mathrm{a}}$ Meal-Q /WFR. There was a statistically significant difference in $\mathrm{CO}_{2} \mathrm{e}$ between WFR and Meal-Q. Crude $P=0.00$, Energy-adjusted $P=0.00$, for Wilcoxon signed rank test

respectively and the Spearman correlation coefficients were $0.56,0.69$ and 0.70 respectively.

The crude daily mean $\mathrm{CO}_{2} \mathrm{e}$ assessed with the first Meal-Q was $3.86 \mathrm{~kg} \mathrm{CO}_{2} \mathrm{e}$ compared to $3.87 \mathrm{~kg} \mathrm{CO}_{2} \mathrm{e}$ with the second Meal-Q for the 87 participants included in the reproducibility analysis (Table 4 ). The differences in crude and energy-adjusted emissions between the first and second Meal-Q were not statistically significant. When participants were divided into quartiles according to their crude and energy-adjusted daily average $\mathrm{CO}_{2} \mathrm{e}$ with the first and second Meal-Q, $56.3 \%$ and $63.2 \%$ of the participants were classified into the same quartile. The proportions classified into the same or adjacent quartile were $88.5 \%$ and $94.3 \%$ respectively for crude and energy-adjusted daily $\mathrm{CO}_{2} \mathrm{e}$, while $2.3 \%$ and $1.1 \%$ were classified into extreme quartiles. Crude and energy-adjusted intraclass correlation coefficients (ICCs) were 0.72 and 0.81 respectively (Table 3 ).

A scatter and a Bland-Altman plot of energy-adjusted daily $\mathrm{CO}_{2} \mathrm{e}$ from the first and second Meal-Q are displayed in Figs. 3 and 4, respectively. The scatter plot showed slightly higher $\mathrm{CO}_{2} \mathrm{e}$ at higher emissions for the second Meal-Q compared to the first. The BlandAltman plot showed a near zero mean difference between the questionnaires and equal estimations over the $\mathrm{CO}_{2} \mathrm{e}$ range. The scatter and Bland-Altman plots for crude daily $\mathrm{CO}_{2} \mathrm{e}$ were similar (see Additional file 1: Fig. S3 and S4).

\section{Discussion}

Foods associated with high GHGE are mainly meat and dairy products [2], but there are large variations within these food groups. For example, the $\mathrm{CO}_{2} \mathrm{e}$ for one $\mathrm{kg}$ of beef is almost $48 \mathrm{~kg} \mathrm{CO} 2$ e after taking unavoidable and avoidable waste and food preparation into account. The corresponding value for one $\mathrm{kg}$ of poultry is about $4 \mathrm{~kg} \mathrm{CO} \mathrm{CO}_{2}$. Despite the fact that Meal-Q is a relatively short questionnaire, we managed to capture the varying contribution of $\mathrm{CO}_{2} \mathrm{e}$ from different sources, which is shown in the validation analyses. Also, the good ability to rank individuals according to $\mathrm{CO}_{2} \mathrm{e}$ makes the method suitable 




Fig. 1 Scatter plot with energy-adjusted $\mathrm{CO}_{2} \mathrm{e}$ assessed by Meal-Q on the vertical axis and energy-adjusted $\mathrm{CO}_{2} \mathrm{e}$ assessed by WFR on the horizontal axis, for participants included in the validation analysis $(n=166)$. The outlier to the right is a person on a low carbohydrate high fat diet. The scatter plot for crude $\mathrm{CO}_{2}$ e was similar (see Additional file 1: Fig. S1). $\mathrm{CO}_{2} \mathrm{e}$, carbon dioxide equivalents. WFR, weighed food record

for future epidemiological association studies, where accurate ranking is more important than the absolute magnitude of exposure [22]. Furthermore, results from the repeated assessments of Meal-Q show that the method has high reproducibility.
This is the first study validating diet-related GHGE from a FFQ compared to a 7-day WFR, therefore, comparisons with previous studies are difficult. However, there are studies evaluating the assessment of specific food products, such as beef and cheese. Overall, our

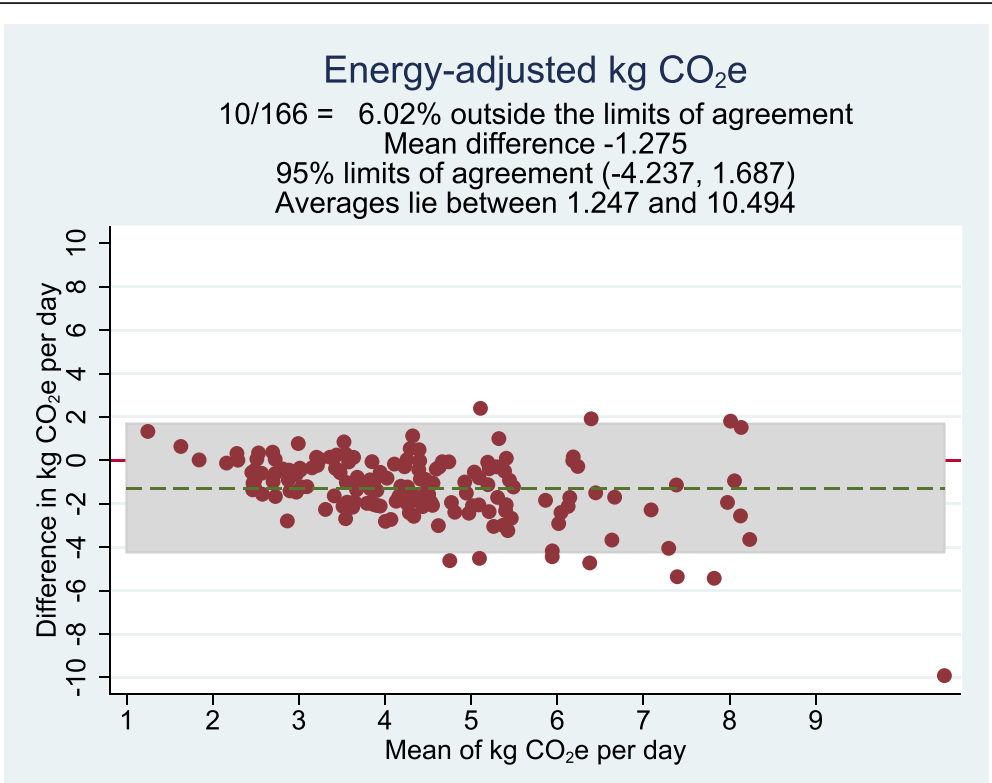

Fig. 2 Bland-Altman plot showing the difference in energy-adjusted $\mathrm{CO}_{2} \mathrm{e}$ assessed by Meal-Q and the WFR plotted against the mean of the two methods, for participants included in the validation analysis $(n=166)$. Each data point represents one subject. The grey background show the 95\% limits of agreement. The Bland-Altman plot for crude $\mathrm{CO}_{2}$ e was similar (see Additional file 1: Fig. S2). $\mathrm{CO}_{2} \mathrm{e}$, carbon dioxide equivalents. WFR, weighed food record 
Table 3 Pearson, Spearman and intraclass correlation coefficients of daily $\mathrm{CO}_{2} \mathrm{e}$

\begin{tabular}{llll}
\hline & Crude $(95 \% \mathrm{Cl})$ & Energy-adjusted $(95 \% \mathrm{Cl})$ & Energy-adjusted and deattenuated $(95 \% \mathrm{Cl})$ \\
\hline Pearson corr. coefficients $^{\mathrm{a}, \mathrm{b}}$ & $0.56(0.46,0.66)$ & $0.67(0.59,0.76)$ & $0.68(0.59,0.76)$ \\
Spearman corr. coefficients $^{\mathrm{b}}$ & $0.56(0.44,0.67)$ & $0.69(0.61,0.77)$ & $0.70(0.61,0.77)$ \\
Intraclass corr. coefficients $^{c}$ & $0.72(0.60,0.81)$ & $0.81(0.73,0.87)$ & \\
\hline
\end{tabular}

Pearson correlation coefficients and Spearman correlation coefficients of daily $\mathrm{CO}_{2} \mathrm{e}$ between Meal-Q and the WFR. Intraclass correlation coefficients of daily $\mathrm{CO}_{2} \mathrm{e}$ between first and second Meal-Q

$\mathrm{CO}_{2}$ e Carbon dioxide equivalents, WFR Weighed food record

${ }^{\mathrm{a}}$ Log transformed data. ${ }^{\mathrm{b}}$ Validity analyses, $n=166$. ${ }^{\mathrm{C}}$ Reproducibility analyses, $n=87$

results regarding diet-related GHGE are in line with results from validation studies on food products that are associated with high GHGE with regards to correlation coefficients, Bland-Altman plots, classification into the same or adjacent quintile and reproducibility [28-32].

To validate a new dietary assessment method is a challenge since the methods used differ from each other in several ways and perfect agreement between the two methods cannot be expected. Simultaneously, it is these inherent differences that make them suitable for validation studies, due to their largely independent errors. Meal-Q is a short user-friendly web-questionnaire that assesses habitual dietary intake retrospectively during the past few months, and only takes, on average, about 17 min to complete [14]. It takes advantage of an interactive design with extensive skip patterns, pre-defined food items and intake frequencies, uses standard portion sizes for most items, and only offers limited possibilities to personalize portion size for cooked dishes using photos. WFR on the other hand, aims to assess the total consumption of food and beverages during seven specific days. The dietary assessment is prospective, openended and personalized, but the participation burden is high, as the participants need to weigh and record everything they consume for a week. Given how different the two methods are, one would expect the estimates of the absolute diet-related GHGE to differ. This is also confirmed in the plots, where the energy-adjusted BlandAltman plot shows that Meal-Q underestimates $\mathrm{CO}_{2} \mathrm{e}$ compared to WFR. Also, the underestimation increased as $\mathrm{CO}_{2} \mathrm{e}$ increased. There could be several reasons to why Meal-Q underestimates higher emissions, such as limited number of food items, that the largest intake frequencies were not high enough, that the portion sizes shown in the photos were too small or that the standard portion sizes used for the rest of the food items were too small to accurately assess the intake for some people. However, the data from the FFQ in epidemiological studies is used to rank individuals according to their exposure to enable risk comparisons between exposure groups, and the ranking of individuals according to their $\mathrm{CO}_{2} \mathrm{e}$ showed good agreement in the present study. In future epidemiological studies, Meal-Q will be used to assess diet-related $\mathrm{CO}_{2} \mathrm{e}$ and rank individuals with regard to their $\mathrm{CO}_{2} \mathrm{e}$. The prevalence of various health outcomes will thereafter be compared between groups with food habits that contribute to high and low levels of $\mathrm{CO}_{2} \mathrm{e}$, respectively, in order to study if climatefriendly food habits are also healthy food habits.

The study benefits from having LCA data for a large number of food items. Although there are inevitable uncertainties with LCA data, we have similar system boundaries for all food items. Also, as suggested by a recent review [33], we corrected the LCA values for weight change during food preparation, for example making the $\mathrm{CO}_{2} \mathrm{e}$ for rice correspond to cooked instead of dry rice, and compensated for unavoidable as well as avoidable food losses both before and after food preparation. To separate the contribution of $\mathrm{CO}_{2} \mathrm{e}$ from different meats, Meal-Q included questions on how often the participants consume the following meat products: chicken, beef, pork, ground meat dishes, bacon, lamb and game, offal, and hamburgers, respectively. Moreover, for ground meat dishes, such as meatballs, we used a mix of beef and pork based on standard recipes from the Swedish food composition database.

Table $4 \mathrm{CO}_{2}$ e assessed by first and second Meal-Q for participants in the reproducibility analysis

\begin{tabular}{|c|c|c|c|c|c|c|}
\hline & \multicolumn{3}{|c|}{ Crude $\mathrm{kg} \mathrm{CO}_{2}$ e per day } & \multicolumn{3}{|c|}{ Energy-adjusted $\mathrm{kg} \mathrm{CO}_{2}$ e per day } \\
\hline & $\overline{\text { Mean }}$ & Median & $(\mathrm{IQR})$ & $\overline{M e a n}$ & Median & (IQR) \\
\hline First Meal-Q & 3.86 & 3.55 & $(2.20)$ & 3.86 & 3.58 & $(1.87)$ \\
\hline Second Meal-Q & 3.87 & 3.64 & $(2.06)$ & 3.87 & 3.37 & $(1.94)$ \\
\hline Difference $^{a}$ & 0.01 & 0.01 & & 0.01 & 0.04 & \\
\hline
\end{tabular}

Crude and energy-adjusted daily mean, median and IQR of daily $\mathrm{CO}_{2} \mathrm{e}$ assessed by first and second Meal-Q for participants in the reproducibility analysis $(n=87)$ $I Q R$ Interquartile range, $\mathrm{CO}_{2} e$ Carbon dioxide equivalents

${ }^{a}$ Individual differences between the first and second Meal-Q. There was no statistically significant difference in $\mathrm{CO}_{2} \mathrm{e}$ between first and second Meal-Q. Crude $P=$ 0.58 , energy-adjusted $P=0.49$, for Wilcoxon signed rank test 




Fig. 3 Scatter plot with energy-adjusted $\mathrm{CO}_{2} \mathrm{e}$ assessed by the first Meal-Q on the vertical axis and energy-adjusted $\mathrm{CO}_{2} \mathrm{e}$ assessed by the second Meal-Q on the horizontal axis, for participants included in the reproducibility analysis $(n=87)$. The scatter plot for $\mathrm{crude} \mathrm{CO}_{2} \mathrm{e}$ was similar (see Additional file 1: Fig. S3). $\mathrm{CO}_{2} \mathrm{e}$, carbon dioxide equivalents

Dairy products included in the questionnaire were milk, yoghurt, hot cocoa, cheese (hard and soft, respectively), ice cream, and dishes rich in dairy products such as pancakes and pizza. One uncertainty lies in the handling of mixed dishes, such as lasagna. All mixed dishes were divided into up to three main food products or groups and the $\mathrm{CO}_{2} \mathrm{e}$ values were weighted based on these. We have not evaluated the sensitivity of this approach and it is a potential source of bias. However, we estimated that the three main food products or groups in mixed dishes would be sufficient to assign an average LCA value.

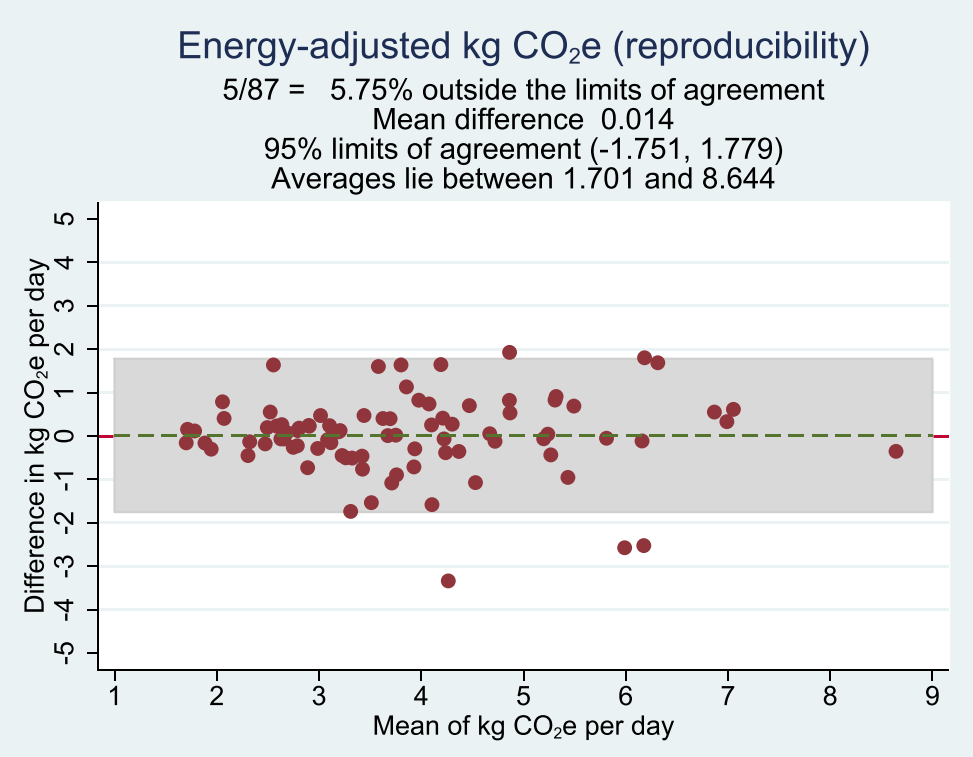

Fig. 4 Bland-Altman plot showing the difference in energy-adjusted $\mathrm{CO}_{2} \mathrm{e}$ assessed by the first and second Meal-Q plotted against the mean of the two methods, for participants included in the reproducibility analysis $(n=87)$. Each data point represents one subject. The grey background show the $95 \%$ limits of agreement. The Bland-Altman plot for crude $\mathrm{CO}_{2}$ e was similar (see Additional file 1: Fig. S4). $\mathrm{CO}_{2} \mathrm{e}$, carbon dioxide equivalents 
Strengths in the study include its large sample size, only a few dropouts and high compliance with all parts of the study. Acknowledging that the participants were self-selected, highly educated, mainly female and that several had a background in nutrition, they were likely more motivated to be precise and complete the study than a random sample of the population would have been. Even though this contributes positively to the internal validity, it may decrease the external validity, i.e. the ability to generalize to the whole Swedish population. The short time period between the first and second Meal-Q makes changes in participant's dietary habits less likely. However, if participants remembered their earlier answers, then reproducibility may have been overestimated. Also, true changes in dietary intake cannot be separated from measurement errors in reproducibility analyses [22]. While a low reproducibility would be a clear sign that the questionnaire is unsuitable to measure long-term intake, a high reproducibility does not prove correctness of the questionnaire, seeing that it may be as a result of correlated errors in the first and second administration of the questionnaire. Moreover, both Meal-Q and the WFR were web-based which enhance the quality of the data due to reduction of coding errors and missing data. Also, assessment of physical activity made us able to identify and exclude underreporters of energy.

Here we present two types of correlation coefficients, although, their use in validation studies is disputed due to the risk of being misleading since they measure the linear relationship between two methods rather than the absolute agreement between them [22]. Therefore, to give a more nuanced picture, we also included BlandAltman plots and scatter plots, along with crossclassification analyses.

Recent studies estimated diet-related GHGE using FFQs in the European Prospective Investigation into Cancer and Nutrition (EPIC) cohort [34, 35] and the Adventist Health Study 2 [36]. This is an emerging line of research and highlights the need for dietary assessment methods validated specifically with regards to $\mathrm{CO}_{2} \mathrm{e}$.

\section{Conclusions}

This is the first study validating the assessment of dietrelated GHGE by a short FFQ. The results suggest that Meal-Q is a useful tool for studying the link between diet and $\mathrm{CO}_{2} \mathrm{e}$ in future epidemiological studies.

\section{Additional file}

Additional file 1: Table S1. Data from life cycle assessment (LCA) studies expressed as carbon dioxide equivalents $\left(\mathrm{CO}_{2} \mathrm{e}\right)$ per $\mathrm{kg}$ of food product. Fig. S1. Scatter plot with crude $\mathrm{CO}_{2} \mathrm{e}$ assessed by Meal-Q on the vertical axis and crude $\mathrm{CO}_{2}$ e assessed by WFR on the horizontal axis, for participants included in the validation analysis. Fig. S2. Bland-Altman plot showing the difference in crude $\mathrm{CO}_{2}$ e assessed by Meal-Q and the WFR plotted against the mean of the two methods, for participants included in the validation analysis. Fig. S3. Scatter plot with crude $\mathrm{CO}_{2} \mathrm{e}$ assessed by the first Meal-Q on the vertical axis and crude $\mathrm{CO}_{2} \mathrm{e}$ assessed by the second Meal-Q on the horizontal axis, for participants included in the reproducibility analysis. Fig. S4. Bland-Altman plot showing the difference in crude $\mathrm{CO}_{2} \mathrm{e}$ assessed by the first and second Meal-Q plotted against the mean of the two methods, for participants included in the reproducibility analysis. (DOCX $56 \mathrm{~kb}$ )

\section{Abbreviations}

$\mathrm{CO}_{2} \mathrm{e}$ : Carbon dioxide equivalents; $\mathrm{FFQ}$ : Food frequency questionnaire; GHGE: Greenhouse gas emission; GWP: Global warming potential; LCA: Life cycle assessment; PAL: Physical activity level; WFR: Weighed food record.

\section{Competing interests}

The authors declare that they have no competing interests.

\section{Authors' contributions}

CS and FH were responsible for collection of LCA data; KB, OB and SER for development and validation of the nutrient calculation program MealCalc; CS for calculation of $\mathrm{CO}_{2}$; $\mathrm{AS}, \mathrm{CS}$ and $\mathrm{KB}$ for statistical analyses and interpretation of results. CS and KB drafted the manuscript and all authors read and approved the final manuscript.

\section{Acknowledgements}

We thank the participants in the validation study; Elisabeth Möller and Stephanie Bonn for contributions during data collection; Sandra Ekström for invaluable help during calculation of $\mathrm{CO}_{2} \mathrm{e}$ and Annika Tillander for statistical support. This work was supported by grants from the Swedish Research Council and The Alpro Foundation. This manuscript has been subjected to review by The Alpro Foundation and approved for publication.

\section{Author details}

'Department of Medical Epidemiology and Biostatistics, Karolinska Institutet, SE-171 77 Stockholm, Sweden. ${ }^{2}$ Current address: Department of Nutrition, Harvard T.H. Chan School of Public Health, Boston, MA, 02115, USA. ${ }^{3}$ KTH Royal Institute of Technology, School of Computer Science and Communication, SE-100 44 Stockholm, Sweden. ${ }^{4}$ Stanford Graduate School of Education, Stanford, CA, USA. ${ }^{5}$ Department of Energy and Environment, Chalmers University of Technology, SE-412 96 Gothenburg, Sweden.

${ }^{6}$ Stanford Prevention Research Center, Stanford School of Medicine, Stanford, USA.

Received: 22 August 2015 Accepted: 28 January 2016

Published online: 09 February 2016

\section{References}

1. Wirsenius S, Hedenus F, Mohlin K. Greenhouse gas taxes on animal food products: rationale, tax scheme and climate mitigation effects. Clim Chang. 2011:108(1-2):159-84. doi:10.1007/s10584-010-9971-x.

2. Hedenus F, Wirsenius S, Johansson DJA. The importance of reduced meat and dairy consumption for meeting stringent climate change targets. Clim Chang. 2014;124(1-2):79-91. doi:10.1007/s10584-014-1104-5.

3. Macdiarmid JI, Kyle J, Horgan GW, Loe J, Fyfe C, Johnstone A, et al. Sustainable diets for the future: Can we contribute to reducing greenhouse gas emissions by eating a healthy diet? Am J Clin Nutr. 2012;96(3):632-9. doi:10.3945/ajcn.112.038729.

4. Friel S, Barosh $\mathrm{L}$, Lawrence $\mathrm{M}$. Towards healthy and sustainable food consumption: an Australian case study. Public Health Nutr. 2014;17(5):1156-66. doi:10.1017/s1368980013001523.

5. van Dooren C, Marinussen M, Blonk H, Aiking H, Vellinga P. Exploring dietary guidelines based on ecological and nutritional values: A comparison of six dietary patterns. Food Policy. 2014;44(0):36-46. http://dx.doi.org/10.1016/j. foodpol.2013.11.002.

6. Van Kernebeek HRJ, Oosting SJ, Feskens EJM, Gerber PJ, De Boer IJM. The effect of nutritional quality on comparing environmental impacts of human 
diets. J Clean Prod. 2014;73(0):88-99. http://dx.doi.org/10.1016/j.jlepro.2013. 11.028.

7. Masset G, Vieux F, Verger EO, Soler LG, Touazi D, Darmon N. Reducing energy intake and energy density for a sustainable diet: a study based on self-selected diets in French adults. Am J Clin Nutr. 2014;99(6):1460-9. doi:10.3945/ajcn.113.077958.

8. Joyce A, Hallett J, Hannelly T, Carey G, Hallett J, Hannelly T. The impact of nutritional choices on global warming and policy implications: examining the link between dietary choices and greenhouse gas emissions. Energy and Emission Control Technologies. 2014;2:33-43. http://dx.doi.org/10.2147/ EECT.S58518

9. Hallström E, Carlsson-Kanyama A, Börjesson P. Environmental impact of dietary change: a systematic review. J Clean Prod. 2015;91:1-11. http://dx.doi.org/10.1016/j.jclepro.2014.12.008.

10. Yip CS, Crane G, Karnon J. Systematic review of reducing population meat consumption to reduce greenhouse gas emissions and obtain health benefits: effectiveness and models assessments. Int J Public Health. 2013; 58(5):683-93. doi:10.1007/s00038-013-0484-z.

11. Briggs AD, Kehlbacher A, Tiffin R, Garnett T, Rayner M, Scarborough P. Assessing the impact on chronic disease of incorporating the societal cost of greenhouse gases into the price of food: an econometric and comparative risk assessment modelling study. BMJ Open. 2013;3(10), e003543. doi:10.1136/bmjopen-2013-003543.

12. Milner J, Green R, Dangour AD, Haines A, Chalabi Z, Spadaro J, et al. Health effects of adopting low greenhouse gas emission diets in the UK. BMJ Open. 2015;5(4), e007364. doi:10.1136/bmjopen-2014-007364.

13. Roy $P$, Nei $D$, Orikasa $T, X u$ Q, Okadome $H$, Nakamura N, et al. A review of life cycle assessment (LCA) on some food products. J Food Eng. 2009;90(1): 1-10. doi:10.1016/j.jfoodeng.2008.06.016.

14. Christensen SE, Möller E, Bonn SE, Ploner A, Wright A, Sjölander A, et al. Two new meal- and web-based interactive food frequency questionnaires: validation of energy and macronutrient intake. J Med Internet Res. 2013; 15(6), e109. doi:10.2196/jmir.2458.

15. Christensen SE, Moller E, Bonn SE, Ploner A, Balter O, Lissner L, et al. Relative validity of micronutrient and fiber intake assessed with two new interactive meal- and Web-based food frequency questionnaires. J Med Internet Res. 2014;16(2), e59. doi:10.2196/jmir.2965.

16. AhImén K. Maten och miljön. Livscykelanalys av sju livsmedel (The food and the environment. A life cycle assessment study of seven food products). Skövde, Sweden: Swedish. LRF. Sigill Kvalitetssystem AB; 2002. http://www. sigill.se/Global/Folder/maten\%200\%20milj\%c3\%b6n.pdf Archived at: http:/ www.webcitation.org/6fOGPERAH. Accessed February 22016

17. Myhre G, Shindell D, Bréon F, Collins W, Fuglestvedt J, Huang J, et al. Anthropogenic and natural radiative forcing. Cambridge, United Kingdom and New York, NY, USA: Cambridge University Press; 2013.

18. Livsmedelsdatabasen (The Swedish food composition database) [Internet]. Livsmedelsverket (The Swedish National Food Agency), Uppsala. 2015. http://www.livsmedelsverket.se/en/food-and-content/naringsamnen/ livsmedelsdatabasen/ Archived at: http://www.webcitation.org/6XsitxrZb Accessed August 192015

19. Quested T, Johnson H. Household Food and Drink Waste in the UK. Banbury: Report prepared by Waste and Resources Action Programme (WRAP); 2009. ISBN 1-84405-430-6.

20. Gustavsson J, Cederberg C, Sonesson U, Emanuelsson A. The methodology of the FAO study: "Global Food Losses and Food Waste - extent, causes and prevention" - FAO, 2011. Göteborg, Sweden. 2013. SIK report No. 857.

21. Black AE. Critical evaluation of energy intake using the Goldberg cut-off for energy intake:basal metabolic rate. A practical guide to its calculation, use and limitations. Int J Obes Relat Metab Disord. 2000;24(9):1119-30.

22. Willett W. Nutritional epidemiology. 3rd ed. Monographs in epidemiology and biostatistics, vol 40. Oxford. New York: Oxford University Press; 2013.

23. Bland JM, Altman DG. Statistical methods for assessing agreement between two methods of clinical measurement. Lancet. 1986; (8476):307-10.

24. Beaton GH, Milner J, McGuire V, Feather TE, Little JA. Source of variance in 24-hour dietary recall data: implications for nutrition study design and interpretation. Carbohydrate sources, vitamins, and minerals. Am J Clin Nutr. 1983;37(6):986-95.

25. Liu K, Stamler J, Dyer A, McKeever J, McKeever P. Statistical methods to assess and minimize the role of intra-individual variability in obscuring the relationship between dietary lipids and serum cholesterol. J Chronic Dis. 1978;31(6-7):399-418.
26. Rosner B, Willett WC. Interval estimates for correlation coefficients corrected for within-person variation: implications for study design and hypothesis testing. Am J Epidemiol. 1988;127(2):377-86.

27. Lee J, Koh D, Ong CN. Statistical evaluation of agreement between two methods for measuring a quantitative variable. Comput Biol Med. 1989; 19(1):61-70.

28. Jaceldo-Siegl K, Fan J, Sabate J, Knutsen SF, Haddad E, Beeson WL, et al. Race-specific validation of food intake obtained from a comprehensive FFQ: the Adventist Health Study-2. Public Health Nutr. 2011;14(11):1988-97. doi:10.1017/s1368980011000735.

29. Loy SL, Marhazlina M, Nor AY, Hamid JJ. Development, validity and reproducibility of a food frequency questionnaire in pregnancy for the Universiti Sains Malaysia birth cohort study. Malays J Nutr. 2011;17(1):1-18.

30. Date C, Fukui M, Yamamoto A, Wakai K, Ozeki A, Motohashi Y, et al. Reproducibility and validity of a self-administered food frequency questionnaire used in the JACC study. J Epidemiol. 2005;15 Suppl 1:S9-23.

31. Brinkman MT, Kellen E, Zeegers MP, van Dongen MC, Dagnelie PC, Muls E, et al. Validation of the IMMIDIET food frequency questionnaire in an adult Belgian population: a report from the Belgian case-control study on bladder cancer risk. Acta Clin Belg. 2011;66(1):18-25. doi:10.2143/acb.66.1. 2062509.

32. Beck KL, Kruger R, Conlon CA, Heath AL, Coad J, Matthys C, et al. The relative validity and reproducibility of an iron food frequency questionnaire for identifying iron-related dietary patterns in young women. J Acad Nutr Diet. 2012;112(8):1177-87. doi:10.1016/j.jand.2012.05.012.

33. Heller MC, Keoleian GA, Willett WC. Toward a life cycle-based, diet-level framework for food environmental impact and nutritional quality assessment: a critical review. Environ Sci Tech. 2013;47(22):12632-47. doi:10.1021/es4025113.

34. Scarborough P, Appleby PN, Mizdrak A, Briggs ADM, Travis RC, Bradbury KE, et al. Dietary greenhouse gas emissions of meat-eaters, fish-eaters, vegetarians and vegans in the UK. Clim Chang. 2014. doi:10.1007/s10584-014-1169-1.

35. Biesbroek S, Bueno-de-Mesquita HB, Peeters PH, Verschuren WM, van der Schouw YT, Kramer GF, et al. Reducing our environmental footprint and improving our health: greenhouse gas emission and land use of usual diet and mortality in EPIC-NL: a prospective cohort study. Environ Health. 2014; 13(1):27. doi:10.1186/1476-069X-13-27.

36. Soret S, Mejia A, Batech M, Jaceldo-Siegl K, Harwatt H, Sabaté J. Climate change mitigation and health effects of varied dietary patterns in real-life settings throughout North America. Am J Clin Nutr. 2014;100(Supplement 1):490S-5. doi:10.3945/ajcn.113.071589.

\section{Submit your next manuscript to BioMed Central and we will help you at every step:}

- We accept pre-submission inquiries

- Our selector tool helps you to find the most relevant journal

- We provide round the clock customer support

- Convenient online submission

- Thorough peer review

- Inclusion in PubMed and all major indexing services

- Maximum visibility for your research

Submit your manuscript at www.biomedcentral.com/submit
Biomed Central 